\title{
Neutrophil-to-lymphocyte ratio is modality to predict recurrence, disability and mortality of ischemic stroke following acute phase
}

\author{
Chandra Wirawan' ${ }^{1}$ I Putu Eka Widyadharma² \\ ${ }^{1}$ General practitioner, Dumai General Hospital, Riau, Indonesia \\ ${ }^{2}$ Department of Neurology, Faculty of Medicine, Udayana University/Sanglah General Hospital, Bali, Indonesia
}

\begin{abstract}
Stroke has been known as the second greatest cause of mortality and the third cause of disability. Ischemic stroke is more frequent than hemorrhagic stroke. The pathophysiology of ischemic stroke relates with inflammatory process. Neutrophil and lymphocyte are part of that process. Routine peripheral hematological laboratory, which contains information of neutrophil and lymphocyte, is easy, cheap and rapid test. This literature review purposes to explain the modality of neutrophil-lymphocyte ratio (NLR) in predicting the recurrence, disability and mortality of ischemic stroke following acute phase.
\end{abstract}

Keywords: disability, ischemic stroke, mortality, NLR, recurrence, stroke

\section{INTRODUCTION}

Stroke is a sudden neurological deficit which is caused by vascular and can be focally or globally (1). WHO reported that one of six people would have experience of stroke in their lifespan (2). Based on World Health Organization (WHO), the second-leading cause of death (75.2\%) and the third-leading cause of disability (81\%) are stroke. Mortality rate of stroke is higher in Asia and Indonesia is the second highest after Mongolia (3). Prevalence of stroke in Indonesia based on Indonesia's health research by the year 2018 is $10.9 \%$ and stroke is the major cause of disability $(3,382.2 / 100,000$ people-years) and mortality (193.3/100,000 people-years) in older adult $(3,4)$.

Generally, there are two major classifications of stroke, such as ischemic stroke and hemorrhagic stroke. Ischemic stroke is infarction in focal cerebral, spinal, or retinal and cause episodic neurological dysfunction (5). Ischemic stroke is more frequently (80\%) than hemorrhagic stroke. Subtype of ischemic stroke are classified by the etiology, such as cardioembolic, atherosclerosis, lacunar, un- known cause and other cause of ischemic stroke (6). Diagnosis of ischemic stroke is made by clinical history, physical examination (including funduscopic examination) and radiographic imaging (Computed Tomography/CT-Scan, Magnetic Resonance Imaging/MRI, CT/MR angiography, transcranial doppler). Rarely, serum biomarker (S100 calcium binding protein B/S100B) and neuropathological evaluation are used in diagnosis of ischemic stroke (1).

The modality to assess disability of patient who suffered stroke is modified Rankin Scale (mRS). Score of mRS is divided into some categories, such as from 0 (no symptoms at all) to 5 (severe disability and always needs nursing care in all of their activity) and 6 being death (7).

Recurrent ischemic stroke means a recent neurological deficit of an existing deficit. The prevalence of recurrent ischemic stroke is higher in five years following ischemic stroke than two years following ischemic stroke (16\% vs. $12.9 \%)(9,10)$. About $50 \%$ stroke patient who is more than 60 years old, have a higher chance of having recurrent stroke and male is more likely than female (10). There is an 
approximately $38.7 \%$ patient of stroke do not control regularly (4). Irregular control is the main contribution of recurrent stroke besides metabolic diseases, such as diabetes mellitus, hypertension and obesity (10). The irregularly control fails to have proper secondary management. Therefore, it promotes the chance of having recurrent stroke. Furthermore, the recurrent ischemic stroke is caused by both irregularly control and various risk factors of stroke. Prevention of recurrent ischemic stroke depends on the management of the risk factors $(9,10)$. Stroke survivor has limitation to do activity daily living (ADL) because alteration in mobility, behavior, emotion, and articulation. This limitation can be one of the recurrent stroke risk factors. Mortality and disability were more frequent in recurrent stroke group.

The pathophysiology of stroke is related with the complexity of inflammatory process and oxidative stress. There are many inflammatory mediators which play a key role in neutrophil infiltration to ischemic brain's neuron. In the other hand, leukocyte infiltration to the ischemic site is caused by chemokine's expression in endothelial cell (11). In the acute phase, high concentration of leukocyte in intravascular can correlate with the substantial of the infarction and severity of the ischemic brain, whereas low concentration of this blood component is associated with poorer prognosis in chronic phase (12).

NLR is prognosis predictor for heart failure, acute coronary syndrome, organ cancer, covid-19 and even in ischemic stroke. NLR is the proportion of neutrophil and lymphocyte count (13-17). Recently, NLR can be used to predicting the recurrence of ischemic stroke. This inexpensive, rapid and universal laboratory test as peripheral hematological test (such as, hemoglobin, leukocyte, platelet, and differential white cell count (neutrophil, lymphocyte, monocyte, basophil, eosinophil) is routinely checked, especially in emergency room (12). Therefore, this review aims to outline the modality of NLR ratio in predicting the recurrence, disability and mortality of ischemic stroke following acute phase.

\section{NLR AND RECURRENT ISCHEMIC STROKE}

Ischemic stroke is tightly related with the process of atherosclerosis. Inflammation has played a major role in forming atherosclerosis besides having risk factors and family history. Inflammation process can be detected by peripheral hematology laboratory test. It is inexpensive laboratory test and routinely checked (13). Leucocyte exhibits the incidence of recurrent ischemic stroke. However, there are various subtypes of leucocyte, such as neutro- phil, lymphocyte, monocyte, basophil and eosinophil, which results to lower the sensitivity and specificity of leukocyte. NLR is more sensitive to predict the recurrence rate of ischemic stroke than leucocyte or neutrophil solely (14). Suh reported that the highest predictive value of recurrent ischemic stroke is NLR if compared to other components, as well as white blood cell (WBC), C-reactive protein (CRP) and erythrocyte sedimentation rate (ESR) (15). In addition, chronic ischemic stroke patient has two fold higher risk of getting recurrent ischemic stroke which is detected in MRI (8). A China experiment reported that NLR was independent predictor of recurrent ischemic stroke in acute setting. Furthermore, NLR $>3$ had higher chance to have recurrent ischemic stroke event asides from stroke severity and poor prognosis $(\mathrm{HR}=1.499$; $95 \% \mathrm{CI}$; 1.161-1.935; $\mathrm{p}=0.002)(13,21)$.

There are many cut off variations to predict recurrent ischemic stroke. In China study, the cut off of NLR is 2.97 , with $95 \%$ sensitivity and $53 \%$ specificity $(22,23)$. The other study, high score of mRS was found in NLR $>4$ (ORs/RRs = 3.469; 95\%CI; 1.904 6.320) (19). In Turkey study, the cut off of NLR is 2.6 with high sensitivity and specificity (73\% and 73\% consecutively). This inconsistent and unstandardized cut off of NLR can be due to both insufficient and less variety of sample. Thus, further studies with bigger number of sample should be done to conclude a higher sensitivity and specificity and standardized cut off of NLR in predicting the recurrence rate of ischemic stroke (20).

Neutrophil is the first component of white blood cell (WBC) in vascular. It plays a key role in proinflammatory process and releasing proteolytic enzyme. Endothelial cell releases cytokines which elevate the upregulation of peripheral neutrophil. However, lymphocyte has a contrary effect with neutrophil in atherosclerosis $(13,18,21)$. The high neutrophil and low lymphocyte amount in acute phase lead that NLR can be applied in acute phase to predict the recurrence rate of ischemic stroke (21).

Besides NLR, CRP is one of the inflammation indicators. There was a study which compared NLR and CRP in predicting mortality indicated that NLR was more associated with mortality in ischemic stroke (22). Furthermore, NLR and CRP also can predict the etiology of ischemic stroke. Both of NLR and CRP increase when the etiology of ischemic stroke are atherosclerosis and cardioembolic. Nevertheless, NLR is significantly higher in atherosclerosis than in cardioembolic as the etiology of stroke (23).

NLR is higher in female than male but insignificant. Inflammation maker is affected by estrogen 
which extremely depends on age. Therefore, higher inflammation marker can be detected in peripheral blood laboratory in younger female (24).

Quan reported that high NLR had higher risk of recurrent stroke than low NLR in three month follow-up (OR $=1.8 ; \mathrm{p}=<0.0001 ; 95 \% \mathrm{CI} ; 1.476-2.350)$ and in one year follow-up (OR $=1.878 ; \mathrm{p}=<0.0001$; 95\% CI; 1.546-2.281) (25). The other study showed that high NLR was significantly increasing the risk of recurrent ischemic stroke event $(\mathrm{RR}=2.074$; 95\%CI; 1.485-2.896; $\mathrm{p}=<0.001$ ). The risk of recurrent ischemic stroke was increase when there were both high NLR and comorbid such as, hypertension, hyperlipidemia and current smoking (19).

\section{NLR AND DISABILITY ISCHEMIC STROKE}

Shi reported that NLR significantly correlated with disability of ischemic stroke patient after 3 month of acute ischemic stroke $(\mathrm{OR}=1.17 ; 95 \% \mathrm{CI}$; 1.04-1.34; $p=0.024)(26)$. The other study concluded that moderate-severe disability could be related with high NLR (OR = 2.236; 95\%CI; 1.472-3.397; $\mathrm{p}=<$ 0.001) (27). The higher NLR, the poorer outcome following acute ischemic stroke. In one study which divided mRS into 5 group showed that the increasing of NLR was significantly $(p=0.001)$ proportional with increasing the $\mathrm{mRS}(\mathrm{NLR}=3.99 \pm 0,12 ; \mathrm{mRS}=2$ vs. $\mathrm{NLR}=3.92 \pm 0.51 ; \mathrm{mRS}=3$ vs. $\mathrm{NLR}=4.1 \pm 0.93 ; \mathrm{mRS}$ $=4$ vs. $\mathrm{NLR}=4.05 \pm 0.44 ; \mathrm{mRS}=5$ vs. $\mathrm{NLR}=5.95 \pm 0.39$; $\mathrm{mRS}=6)(28)$. Another study revealed that higher NLR was observed in poor outcome $(\mathrm{mRS} \geq 3)$ in 3 months following ischemic stroke $(p=<0.001)$ (29).

Qun reported that the cut-off of NLR which was significant to differentiate between good and poor outcome ( $\mathrm{p}=<0.001 ; 95 \% \mathrm{CI}$; 0.77-0.81) was 2.9 , with $75 \%$ sensitivity and $61 \%$ specificity (30). NLR $\geq 2$, which had high sensitivity and specificity (90\% \& $96 \%$, consecutively) significantly had linked to unfavourable outcome (mRS $\geq 3$ ) in 3 month after ischemic stroke $(p=<0,001)$ (31). High score of mRS was found in $\mathrm{NLR} \geq 3.51(95 \% \mathrm{CI}=0.727-0.825$, $\mathrm{p}=<0.001$ ). The sensitivity and specificity of NLR $\geq$ 3.51 are $64.6 \%$ and $81.8 \%$, respectively (32). The other study found that $35 \%$ ischemic stroke patient with NLR $\geq 3$ had moderate-severe disability. The cut-off of NLR which was described as unfavourable outcome was 2.39 with $72 \%$ sensitivity and $70.9 \%$ specificity $(\mathrm{OR}=1.455 ; 95 \% \mathrm{CI} ; 1.083-1.956)$ (12). There was another study which exhibited that high NLR (NLR $\geq 3$ ) increased four times higher the risk of moderate-severe disability ( $\mathrm{mRS} \geq 3$ ) with $\mathrm{p}=0.006$ (95\%CI; 1.533-13.046) (18). A Korea study reported that $\mathrm{NLR} \geq 4.12$ increased the risk of major disability with $\mathrm{OR}=2.89(\mathrm{p}=0.002 ; 95 \% \mathrm{CI} ; 1.62-5.12)$ (33). Song exhibited that high NLR linked with severe disability $(\mathrm{ORs} / \mathrm{RRs}=1.851 ; 95 \% \mathrm{CI}=1.325-$
2.584; $\mathrm{p}=<0.001)$. When NLR was high at two continuous days after stroke, it correlated with poor prognosis (ORs/RRs = 1.432; 95\%CI; 1.266-1.619) (19). The other cut-off of NLR was 7 and related with poor outcome (mRS 4-6) $(\mathrm{OR}=2.44$; 95\%CI; $1.73-$ 3.42) (34). This is consistent with $\mathrm{Hu}$, who reported that NLR $\geq 5.87$ showed the poor outcome in 3 months after ischemic stroke $(\mathrm{OR}=2.079 ; 95 \% \mathrm{CI}$; 1.232-3.506; $\mathrm{p}=0.006$ ) with $64.4 \%$ sensitivity and $59.2 \%$ specificity. The sensitivity and specificity could be increased by adding other parameters which were included in the risk factor of ischemic stroke (85.2\% and $75.6 \%$, respectively) (29). However, there was variety of cut-off between Asian and non-Asian population. The NLR was found higher in non-Asian population than in Asian population (9). In the other hand, the variety cut-off of NLR is affected with duration of the stroke. The longer the duration from stroke attack, the more optimal cutoff value to measure the outcome. A Turkey study reported that a significant increase of NLR was observed between admission and 24-hour post-ischemic stroke $(3.58 \pm 2.4$ to $7.04 \pm 5.1 ; \mathrm{p}=<0.001)$ $(35,40)$. Another study exhibited that NLR in the first 24 hours was slightly lower than in 48-72 hours after ischemic stroke (4.29 vs. 4.58). In addition, the specificity (66\%) and sensitivity (76\%) in $48-72$ hours was also higher than in the first 24 hours (56\% specificity and 55\% sensitivity) after ischemic stroke. Furthermore, there were associations among NLR, the duration of stroke attack and disability in ischemic stroke patient. Patient with moderate-severe disability had higher NLR level than with mild disability in 24-48 hours of onset ischemic stroke ( $8.41 \pm 0.91$ vs. $4.93 \pm 0.47 ; \mathrm{p}=0.001)$. Consistently, NLR level in moderate-severe disability was also higher than in mild disability in 48-72 hours of onset ischemic stroke $(8.68 \pm 0.93$ vs. $4.5 \pm 0.51 ; \mathrm{p}=$ 0.009). This study showed that NLR $\geq 4.58$ had 5.58 times suffered moderate-severe disability than $\mathrm{NLR} \leq 4.58$ (95\%CI; 1.99-15.64, $\mathrm{p}=0.001)(36)$ (Table 1).

\section{NLR AND MORTALITY ISCHEMIC STROKE}

CRP, which has been used as mortality predictor in cardiovascular disease, is inferior to NLR (15). Besides CRP, Fan investigated that routine hematologic parameters, such as NLR, which was an inexpensive, practical and objective test, correlated to mortality rate of ischemic stroke (37). NLR was higher in dead patients than in survive patients in ischemic stroke $(p=0.011)(38)$. One study exhibited that the level of NLR was higher in survive patients of ischemic stroke within 30 days than in dead patients (7.1 vs. $5.4 ; p=0.005$ ) (29). Shi reported that NLR linked with 3 months mortality rate following ischemic stroke (26). Other study from China showed 
TABLE 1. The characteristics of NLR in ischemic stroke

\begin{tabular}{|c|c|c|c|c|c|c|c|c|c|c|}
\hline Author & Year & Location & Age (years) & Predictive & $\begin{array}{c}\text { Cut-off } \\
\text { NLR }\end{array}$ & \begin{tabular}{|c|}
$\begin{array}{c}\text { Sensitivity } \\
(\%)\end{array}$ \\
\end{tabular} & $\begin{array}{c}\text { Specificity } \\
(\%)\end{array}$ & \begin{tabular}{|c|} 
OR/RR/ \\
HR
\end{tabular} & $\begin{array}{c}95 \% \\
\mathrm{Cl}\end{array}$ & $p$-value \\
\hline \multirow{2}{*}{$\begin{array}{l}\text { Xue J,, et al. } \\
(12)\end{array}$} & 2017 & China & $61.8 \pm 10.2$ & Disability & 2.39 & 72 & 70.9 & 1.455 & 1.083-1.956 & 0.013 \\
\hline & & China & & Recurrence & 2.39 & - & - & 1.499 & 1.161-1.935 & 0.002 \\
\hline $\begin{array}{l}\text { Angkananard } \\
\text { T, et al. (16) }\end{array}$ & 2018 & Thailand & $34.9-73.2$ & Recurrence & 3.00 & - & - & 2.36 & $1.44-3.89$ & 0.012 \\
\hline $\begin{array}{l}\text { Sun G, } \\
\text { et al. (17) }\end{array}$ & 2020 & China & $47.72 \pm 11.9479$ & Recurrence & 2.97 & 95 & 53 & 2.457 & $1.096-5.508$ & 0.03 \\
\hline \multirow{2}{*}{$\begin{array}{l}\text { Luo Y, } \\
\text { et al. (18) }\end{array}$} & 2020 & China & $62.7 \pm 10.5$ & Recurrence & 2.94 & 69.6 & 77.1 & 4.502 & $0.691-0.843$ & $<0.001$ \\
\hline & & China & & Disability & 3 & - & - & 4.502 & $\begin{array}{l}1.533- \\
13.046\end{array}$ & 0.006 \\
\hline \multirow{3}{*}{$\begin{array}{l}\text { Song SY, } \\
\text { et al. (19) }\end{array}$} & 2019 & China & $\geq 65$ & Recurrence & 4 & - & - & 2.074 & $1.485-2.896$ & $<0.001$ \\
\hline & & China & & Disability & 4 & - & - & 1.851 & $1.325-2.584$ & $<0.001$ \\
\hline & & China & & Mortality & 4 & - & - & 1.220 & 1.105-1.347 & $<0.001$ \\
\hline $\begin{array}{l}\text { Köklü E, } \\
\text { et al. (20) }\end{array}$ & 2016 & Turkey & $60-76$ & Recurrence & 2.6 & 73 & 71 & 7.779 & $\begin{array}{l}3.685- \\
16.424 \\
\end{array}$ & 0.001 \\
\hline $\begin{array}{l}\text { Quan K, } \\
\text { et al. (25) }\end{array}$ & 2019 & China & $56-74$ & Recurrence & 3 & - & - & 1.8 & $1.476-2.350$ & $<0.0001$ \\
\hline \multirow{2}{*}{$\begin{array}{l}\text { Shi J, } \\
\text { et al. (26) }\end{array}$} & 2018 & China & $68.1 \pm 12.0$ & Disability & 3 & - & - & 1.17 & $1.04-1.34$ & 0.024 \\
\hline & & China & & Mortality & 3 & - & - & 1.42 & $1.22-1.72$ & $<0.001$ \\
\hline $\begin{array}{l}\text { Cao X, } \\
\text { et al. (27) } \\
\end{array}$ & 2020 & China & $66.81 \pm 12.58$ & Disability & 3.23 & 59.1 & 70.4 & 2.236 & $1.472-3.397$ & $<0.001$ \\
\hline \multirow{2}{*}{\begin{tabular}{|l} 
Tony AA, \\
et al. (28) \\
\end{tabular}} & 2018 & Egypt & $62.64 \pm 10.99$ & Disability & $3.92 \pm 0.51$ & - & - & - & - & 0.001 \\
\hline & & Egypt & & Mortality & 4.99 & 82.9 & 78.9 & - & - & 0.001 \\
\hline $\begin{array}{l}\text { Hu Y, } \\
\text { et al. (29) }\end{array}$ & 2020 & China & $50-75$ & $\begin{array}{l}\text { Disability } \\
\text { and } \\
\text { mortality }\end{array}$ & 5.87 & 64.4 & 59.2 & 2.079 & $1.232-3.506$ & 0.006 \\
\hline $\begin{array}{l}\text { Qun S, } \\
\text { et al. (30) }\end{array}$ & 2017 & China & $69-72$ & Disability & 2.995 & 75 & 61 & 2.547 & $0.77-0.81$ & $<0.001$ \\
\hline $\begin{array}{l}\text { Elsheikh WM, } \\
\text { et al. (31) }\end{array}$ & 2020 & Egypt & $48-70$ & Disability & 2.05 & 90 & 96 & 0.095 & $0.063-0.390$ & 0.001 \\
\hline $\begin{array}{l}\text { Chen C, } \\
\text { et al. (32) }\end{array}$ & 2021 & China & $66.8 \pm 12.2$ & Disability & 3.51 & 64.6 & 81.8 & 2.32 & $0.727-0.825$ & $<0.0001$ \\
\hline $\begin{array}{l}\text { Yu S, } \\
\text { et al. (33) }\end{array}$ & 2017 & Korea & $70.0 \pm 16.0$ & Disability & 4.12 & - & - & 2.89 & $1.62-5.12$ & 0.002 \\
\hline \multirow{2}{*}{$\begin{array}{l}\text { Duan Z, } \\
\text { et al. (34) } \\
\end{array}$} & 2018 & China & $57-74$ & Disability & 7 & - & - & 2.44 & $1.73-3.42$ & $<0.001$ \\
\hline & & & & Mortality & 5.9 & - & - & 6.69 & $1.7-26.3$ & $<0.05$ \\
\hline $\begin{array}{l}\text { Bi Y, } \\
\text { et al. (35) }\end{array}$ & 2021 & China & $62-74$ & Mortality & 3 & - & - & 1.71 & $1.01-2.42$ & $<0.01$ \\
\hline \begin{tabular}{|l} 
Petrone AB, \\
et al. (36)
\end{tabular} & 2019 & USA & $73 \pm 12$ & Disability & 4.58 & 76 & 66 & 5.58 & $1.99-15.64$ & 0.001 \\
\hline $\begin{array}{l}\text { Malhotra K, } \\
\text { et al. (39) }\end{array}$ & 2018 & USA & $64.3 \pm 14.4$ & Mortality & 2.2 & 51.4 & 63.1 & 1.56 & $1.08-2.24$ & 0.018 \\
\hline $\begin{array}{l}\text { Kozyolkin O, } \\
\text { et al. (40) }\end{array}$ & 2019 & Ukraine & $45-85$ & Mortality & 4.8 & 80 & 86.5 & 1.11 & $1.00-1.21$ & 0.0303 \\
\hline
\end{tabular}

that NLR $>3.23$ was corelated with 90 days mortality following ischemic stroke $(\mathrm{p}=<0.001)$ (27). High $\operatorname{NLR}(\geq 4.12)$ has 2.61 times higher mortality rate than low NLR $(\leq 4.12)$ (33). A study in USA reported that 3 month high-mortality rate was found in high NLR $(p=0.018)$ (39). Song demonstrated that the mortality rate had association with NLR level. The higher level of NLR linked with higher mortality rate in 30 days (HR=1.220; 95\%CI; 1.105-1.347; $\mathrm{p}=<$ $0.001)$, 60 days ( $\mathrm{HR}=3.300 ; 95 \% \mathrm{CI} ; 1.350-8.068 ; \mathrm{p}=$ 0.009 ) and one year after 90 days follow-up (HR= 1.030; 95\%CI; 1.010-1.050; $p=0.003$ ) (19). Furthermore, high NLR also related with high mortality rate in recurrent ischemic stroke (40). This could be in consequence of chronic low-grade inflammatory circumstances in existing prior stroke. In addition, 
it could be also caused by the rapid inflammatory response which was released when patient had recurrent stroke (25). NLR could be used to predict the lethal outcome at the time of admission with $80 \%$ sensitivity and $86.5 \%$ specificity $(\mathrm{OR}=1.11$; $95 \% \mathrm{CI}$; 1.00-1.21; $\mathrm{p}=0.0303$ ) (40). In Egypt study, NLR $\geq 4.99$ could predict the mortality of ischemic stroke with high specificity and sensitivity $(\mathrm{p}=0.001 ; 78.9 \%$ and $82.9 \%$, respectively) (28). Moreover, NLR could be used to predict 3 month mortality rate in acute ischemic stroke. High NLR related with higher risk of 3 month mortality rate following acute ischemic stroke (95\%CI; 1.01-2.42, $\mathrm{p}=<0.01$ ) (35). Malhotra reported that the cut-off of NLR, which associated with 3-month mortality rate, was 2.2. Patient who died 3 month after ischemic stroke had NLR $>2.2$ (P: 0.018) (39). The management of ischemic stroke as early prevention could decline the risk of mortality, which caused by ischemic stroke and adjust the NLR (35). The mortality rate also correlated with time of follow-up and NLR after ischemic stroke.
The association of NLR and mortality rate decreased overtime especially after two years follow-up. High NLR level has twice risk of dead in the first two years after ischemic stroke (41).

\section{CONCLUSIONS}

Besides CRP, WBC and other hematologic laboratory parameters, NLR is practical, rapid and inexpensive test, which have been used routinely checked. NLR has high sensitivity and specificity, which can be used to predicting the recurrence, disability, and mortality of ischemic stroke. High NLR correlates with high risk of recurrence, moderate-severe disability, and mortality rate of ischemic stroke. The cut-off of NLR is still very diverse. Therefore, further research with bigger number of sample requires to perform in order to obtain cut-off based on age, sex, comorbid, onset of stroke and other factors which can influence the level of NLR.

\section{Conflict of interest: none declared Financial support: none declared}

\section{REFERENCES}

1. Sacco RL, Kasner SE, Broderick JP, et al.; American Heart Association Stroke Council, Council on Cardiovascular Surgery and Anesthesia; Council on Cardiovascular Radiology and Intervention; Council on Cardiovascular and Stroke Nursing; Council on Epidemiology and Prevention; Council on Peripheral Vascular Disease; Council on Nutrition, Physical Activity and Metabolism. An updated definition of stroke for the 21st century: a statement for healthcare professionals from the American Heart Association/American Stroke Association. Stroke. 2013 Jul;44(7):2064-89.

2. Feigin VL, Norrving B, Mensah GA, et al. Stroke Compendium Global Burden of Stroke Effects of Neurologic Injury on Cardiovascular Function Vascular Cognitive Impairment. Circ Res. 2017;3:439-448.

3. Venketasubramanian N, Yoon BW, Pandian J, Navarro JC. Stroke Epidemiology in South, East, and South-East Asia: A Review. J Stroke. 2017 Sep;19(3):286-294.

4. Riset Kesehatan Dasar. Laporan_Nasional_RKD2018_FINAL.pdf. Badan Penelitian dan Pengembangan Kesehatan. 2018. p. 221-222. Available at: http://labdata.litbang.kemkes.go.id/images/download/laporan/ RKD/2018/Laporan_Nasional_RKD2018_FINAL.pdf.

5. Knight-Greenfield A, Nario JJQ, Gupta A. Causes of Acute Stroke: A Patterned Approach. Radiol Clin North Am. 2019 Nov;57(6):10931108.

6. Boehme AK, Esenwa C, Elkind MS. Stroke Risk Factors, Genetics, and Prevention. Circ Res. 2017 Feb 3;120(3):472-495.

7. Han TS, Fry CH, Gulli G, et al. Prestroke Disability Predicts Adverse Poststroke Outcome: A Registry-Based Prospective Cohort Study of Acute Stroke. Stroke. 2020 Feb;51(2):594-600.

8. Khanevski AN, Bjerkreim AT, Novotny V, et al. Recurrent ischemic stroke: Incidence, predictors, and impact on mortality. Acta Neurol Scand. 2019 Jul; 140(1):3-8.

9. Yi Ying $C$, Harith $S$, Ahmad A, Basri Mukhali H. Prevalence, risk factors and secondary prevention of stroke recurrence in eight countries from south, east and southeast asia: a scoping review. Med J Malaysia. 2018;73(2):90-99.

10. Li X, Li X, Fang F, et al. Is Metabolic Syndrome Associated with the Risk of Recurrent Stroke: A Meta-Analysis of Cohort Studies. Vol. 26, Journal of Stroke and Cerebrovascular Diseases. W.B. Saunders. 2017:2700-2705.
11. Pawluk H, Woźniak A, Grześk G, et al. The Role of Selected ProInflammatory Cytokines in Pathogenesis of Ischemic Stroke. Clin Interv Aging. 2020;15:469-484.

12. Xue J, Huang W, Chen X, et al. Neutrophil-to-Lymphocyte Ratio Is a Prognostic Marker in Acute Ischemic Stroke. J Stroke Cerebrovasc Dis. 2017;26(3):650-7.

13. Ma Z, Yue Y, Luo Y, et al. Clinical Utility of the Inflammatory Factors Combined With Lipid Markers in the Diagnostic and Prognostic Assessment of Ischemic Stroke: Based on Logistic Regression Models. J Stroke Cerebrovasc Dis. 2020;29(4):104653.

14. Zhu B, Pan Y, Jing J, et al. Neutrophil counts, neutrophil ratio, and new stroke in minor ischemic stroke or TIA. Neurology. 2018;90(21):E1870-8.

15. Suh B, Shin DW, Kwon HM, et al. Elevated neutrophil to lymphocyte ratio and ischemic stroke risk in generally healthy adults. PLoS One. 2017 Aug 1;12(8).

16. Angkananard T, Anothaisintawee T, Mcevoy M, Attia J, Thakkinstian A. Neutrophil Lymphocyte Ratio and Cardiovascular Disease Risk: A Systematic Review and Meta-Analysis. Biomed Res Int. 2018;2018:11.

17. Sun G, Yang Y, Chen Z, et al. Neutrophil to Lymphocyte Ratio Predicts Outcome of Stroke by Cervicocranial Arterial Dissection. Front Med. 2020;7:1-8.

18. Luo Y, Xia LX, Li ZL, et al. Early neutrophil-to-lymphocyte ratio is a prognostic marker in acute minor stroke or transient ischemic attack. Acta Neurol Belg. 2020 Feb 8.

19. Song SY, Zhao XX, Rajah G, et al. Clinical Significance of Baseline Neutrophil-to-Lymphocyte Ratio in Patients With Ischemic St roke or Hemorrhagic Stroke: An Updated Meta-Analysis. Front Neurol. 2019 Oct 4;10:1032.

20. Köklü E, Yüksel IÖ, Arslan Ș, et al. Is Elevated Neutrophil-toLymphocyte Ratio a Predictor of Stroke in Patients with Intermediate Carotid Artery Stenosis? J Stroke Cerebrovasc Dis. 2016;25(3):578-584.

21. Yilmaz AB, Gokhan $S$, Sener A, Erel O. Analysis of Neutrophil/ Lymphocyte ratio and Thiol/Disulfide homeostasis parameters in patients admitted to the emergency department with ischemic stroke. Pakistan J Med Sci. 2018;34(6):1418-1423.

22. Gundogdu OL, Bilge N, Yalcin A, Ceylan M. Association between biomarkers in the long-term prognosis of ischemic stroke. Ann Med Res. 2019;26(9):1875-1879. 
23. Harpaz D, Seet RCS, Marks RS, Tok AIY. Blood-based biomarkers are associated with different ischemic stroke mechanisms and enable rapid classification between cardioembolic and atherosclerosis etiologies. Diagnostics. 2020;10(10);804.

24. Tavșanlı ME, Ünal E. Inflammatory biomarkers in the young stroke population. Med Sci Discov. 2020;7(9):642-646.

25. Quan K, Wang A, Zhang X, Wang Y. Leukocyte Count and Adverse Clinical Outcomes in Acute Ischemic Stroke Patients. Front Neurol. 2019;10:1-13.

26. Shi J, Peng $H$, You $S$, et al. Increase in Neutrophil after $r$-tPA Thrombolysis Predicts Poor Functional Outcome of Ischemic Stroke: A Longitudinal Study. Eur J Neurol. 2018;25(4):687-e45.

27. Cao X, Zhu Q, Xia X, et al. The correlation between novel peripheral blood cell ratios and 90-day mortality in patients with acute ischemic stroke. PLoS One. 2020 Aug 28;15(8):e0238312.

28. Tony AA, Tony EAE, Mohammed WS, Kholef EF. The Predictive Effect of Mean Platelet Volume (MPV) and Neutrophil-to-Lymphocyte Ratio (NLR) on the Functional Outcome of Acute Ischemic Stroke. Med J Cairo Univ. 2018;86(12):4107-4113.

29. Hu Y, Huang K, Ji Z, et al. High neutrophil-to-lymphocyte ratio is associated with poor clinical outcome in patients with critically ill stroke. Minerva Anestesiol. 2020;86(9):939-947.

30. Qun S, Tang Y, Sun J, et al. Neutrophil-To-Lymphocyte Ratio Predicts 3-Month Outcome of Acute Ischemic Stroke. Neurotox Res. 2017;31(3):444-452.

31. Elsheikh WM, Alahmar IE, Salem GM, Matar ES. New stroke prognostic factors. Egypt J Neurol Psychiatry Neurosurg. 2020;56(1):58.

32. Chen C, Gu L, Chen L, et al. Neutrophil-to-Lymphocyte Ratio and Platelet-to-Lymphocyte Ratio as Potential Predictors of Prognosis in Acute Ischemic Stroke. Front Neurol. 2021 Jan 25;11:525621.
33. Yu S, Arima H, Bertmar $\mathrm{C}$, et al. Neutrophil to lymphocyte ratio and early clinical outcomes in patients with acute ischemic stroke. J Neurol Sci. 2018;387:115-118.

34. Duan Z, Wang H, Wang Z, et al. Neutrophil-lymphocyte ratio predicts functional and safety outcomes after endovascular treatment for acute ischemic stroke. Cerebrovasc Dis. 2018;45(5-6):221-227.

35. Bi Y, Shen J, Chen S-C, et al. Prognostic value of neutrophil to lymphocyte ratio in acute ischemic stroke after reperfusion therapy. Sci Rep. 2021;11:1-11.

36. Petrone AB, Eisenman RD, Steele KN, et al. Temporal dynamics of peripheral neutrophil and lymphocytes following acute ischemic stroke. Neurol Sci. 2019;40(9):1877-1885.

37. Fan L, Gui L, Chai EQ, Wei CJ. Routine hematological parameters are associated with short- and long-term prognosis of patients with ischemic stroke. J Clin Lab Anal. 2018;32(2):1-5.

38. Lök U, Gülaçt U. The Predictive Effect of the Neutrophil-toLymphocyte Ratio (NLR) on the Mortality of Acute Ischemic Stroke and its Subtypes: a Retrospective Cross-Sectional Study. Eurasian J Emerg Med. 2016;15:69-72.

39. Malhotra K, Goyal N, Chang JJ, et al. Differential leukocyte counts on admission predict outcomes in patients with acute ischaemic stroke treated with intravenous thrombolysis. Eur J Neurol. 2018; 25(12):1417-1424.

40. Kozyolkin O, Kuznietsov A, Novikova L. Prediction of the Lethal Outcome of Acute Recurrent Cerebral Ischemic Hemispheric Stroke. Medicina (B Aires). 2019;55(311):1-12.

41. Fest J, Ruiter TR, Groot Koerkamp B, et al. The neutrophil-tolymphocyte ratio is associated with mortality in the general population: The Rotterdam Study. Eur J Epidemiol. 2019 May 15;34(5):463-470. 